\title{
Takotsubo cardiomyopathy in a female patient with acute ureterolithiasis
}

\author{
(DIvana Petrović \\ Juren*, \\ (D) Sandra Prša, \\ (D)Andreja Čleković- \\ Kovačić, \\ (D) Vlasta Soukup \\ Podravec, \\ (D) Kristina Milevoj \\ Križić, \\ (D)Renata Ivanac \\ Janković, \\ (D)Gabrijela Bašković
}

Bjelovar General Hospital, Bjelovar, Croatia
KEYWORDS: Takotsubo cardiomyopathy, catecholamines, apical ballooning, ureterolithiasis.
CITATION: Cardiol Croat. 2019;14(3-4):74-5. | https://doi.org/10.15836/ccar2019.74

*ADDRESS FOR CORRESPONDENCE: Ivana Petrović Juren, Opća bolnica Bjelovar, A. Mihanovića 8, HR-43000 Bjelovar, Croatia. / Phone: +385-43-279-181 / E-mail: ivanapetro@yahoo.co.uk

ORCID: Ivana Petrović Juren, https://orcid.org/0000-0002-2793-3455 • Sandra Prša, https://orcid.org/0000-0001-9639-3918 Andreja Čleković-Kovačić, https://orcid.org/0000-0002-4532-3597 • Vlasta Soukup Podravec, https://orcid.org/0000-0002-4605-0068 Kristina Milevoj Križić, https://orcid.org/0000-0003-2115-3076 • Renata Ivanac Janković, https://orcid.org/0000-0003-4949-3953 Gabrijela Bašković, https://orcid.org/0000-0002-5413-873X

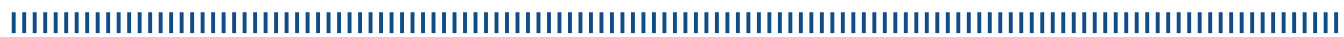

Introduction: Takotsubo (stress cardiomyopathy/transient apical ballooning/broken heart syndrome) is disorder associated with transient left ventricular disfunction. It usually occurs in older women, $50 \%$ of them with neurologic or psychiatric conditions, or after emotional or physical stress, but also in absence of those triggers, and in younger population and men too. An excessive release of catecholamines seems to be pivotal role in the development of stress cardiomyopathy. Usually patients present with acute heart failure or acute coronary syndrome. Echocardiographically is almost undistinguishable from acute myocardial infarction due to left descending coronary artery occlusion. ${ }^{1,2}$

Case report: We herein present the case of 50-years-old female with nonregulated hypertension, dyslipidemia and obesity, presented with renal colic accompanied with nonspecific chest pain and dyspnea within 36 hours before admission. Initially she was presented to urologist due to dilation of channel system of the right kidney; radiographically possible stone in prevesical part of right ureter. Since her electrocardiogram showed subacute myocardial infarction with ST-segment elevation of anteroseptal region (Figure 1) with troponin T elevation up to $0.53 \mathrm{ug} / \mathrm{L}$, she was admitted to Coronary Unit at the Department of Internal Medicine. Echocardiography showed closely suspicions on Takotsubo cardiomyopathy with preserved left ventricular systolic function (Figure 2), no valvular disease or intracavitary gradient. Her laboratory test results showed progression of deterioration of renal function and oliguria (urea 18,3 mmol/l, creatinine $264 \mathrm{mmol} / \mathrm{l}$, eGFR EPI $17.4 \mathrm{~mL} / \mathrm{min}$ ), inflammation markers were high (Leucocytes $19 \times 10^{\circ}$, CRP $270 \mathrm{ug} / \mathrm{L}$ ) predicting urosepsis and obstruction of the right kidney needed to be solved promptly. She was amicably transferred to tertiary center where urologists first resolved kidney obstruction since her kidney function was compromised, and after resolving urosepsis and full recovery she underwent coronarography that confirmed Takotsubo cardiomyopathy with no coronary artery obstruction lesions. Patient was managed with conservative therapy: ACE inhibitors, beta-blockers, analgesics and low molecular weight heparin. After six weeks she came for control

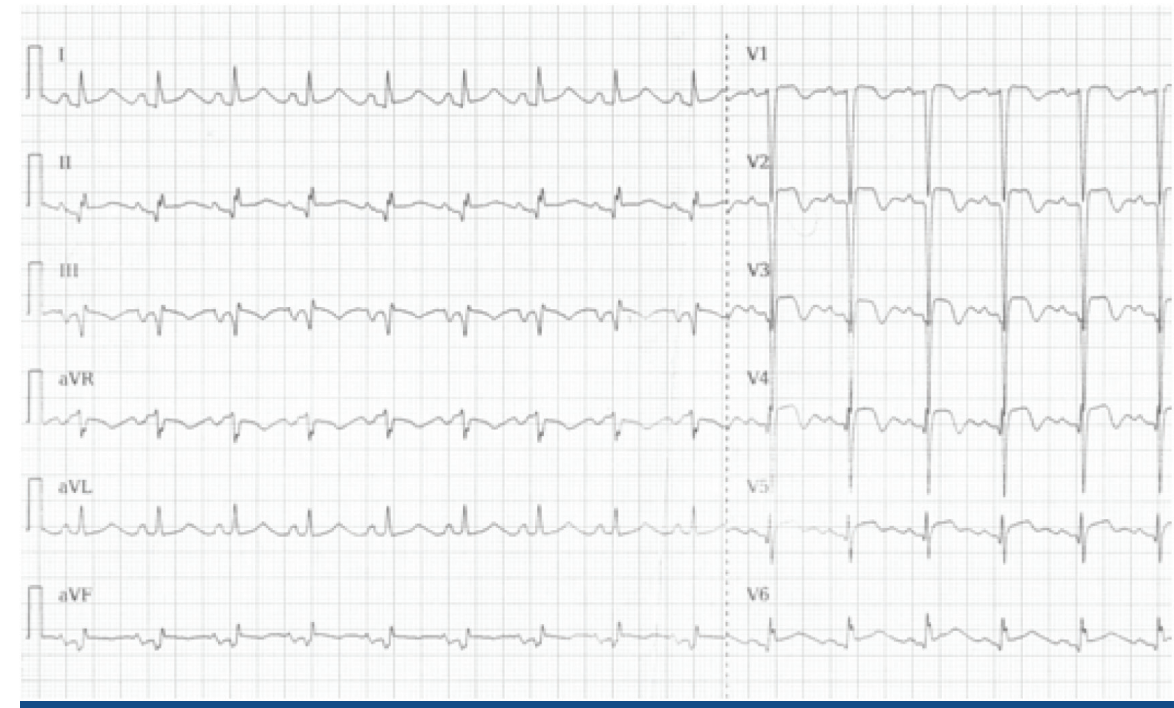

FIGURE 1. Subacute myocardial infarction with ST-segment elevation in the anteroseptal region.
C Cardiologia Croatica

2019:14(3-4):74.
RECEIVED:

February 28, 2019

ACCEPTED:

March 24, 2019

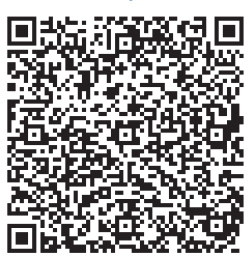

10. hrvatski dvogodišnji ehokardiografski kongres s međunarodnim sudjelovanjem $10^{\text {th }}$ Croatian Biennial Echocardiography Congress with International Participation Poreč, 16. do 18. 5.2019. 
echocardiography examination showing full recovery of apical ballooning and electrocardiographically complete resolution of earlier signs of anteroseptal infarction (Figure 3).
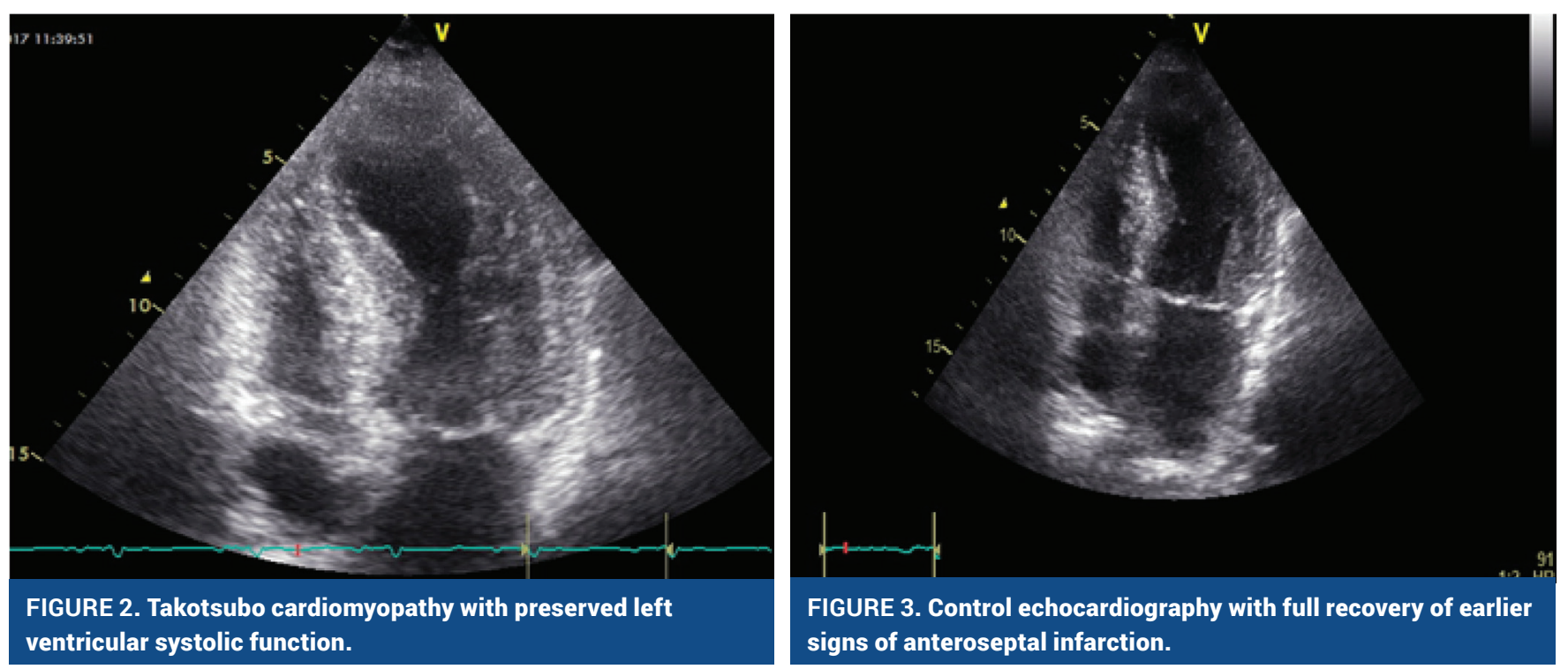

Conclusion: Reversible left ventricular dysfunction (in this case we saw typical wall motion abnormality - apical ballooning with preserved global systolic function) seem to be pathognomonic in Takotsubo syndrome, and timelines of recovery is variable from patient to patient.

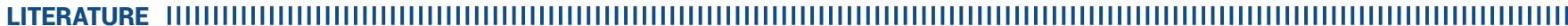

1. Abe Y, Kondo M, Matsouka R, Araki M, Dohyama K, Tanio H. Assessment of clinical features in transient left ventricular apical ballooning. J Am Coll Cardiol. 2003 Mar 5;41(5):737-42. https://doi.org/10.1016/S0735-1097(02)02925-X

2. Tsuchihashi K, Ueshima K, Uchida T, Oh-mura N, Kimura K, Owa M, et al; Angina Pectoris-Myocardial Infarction Investigations in Japan. Transient left ventricular apical ballooning without coronary artery stenosis: a novel heart syndrome mimicking acute myocardial infarction. Angina Pectoris-Myocardial Infarction Investigations in Japan. J Am Coll Cardiol. 2001 Jul;38(1):11-8. https://doi.org/10.1016/S0735-1097(01)01316-X 